\title{
Uterine disorders and pregnancy complications: insights from mouse models
}

\author{
Hyunjung Jade Lim ${ }^{1}$ and Haibin Wang ${ }^{2}$
}

${ }^{1}$ Department of Biomedical Science and Technology, Institute of Biomedical Science and Technology, Research Center for Transcription Control, Konkuk University, Seoul, Korea. ${ }^{2}$ State Key Laboratory of Reproductive Biology, Institute of Zoology, Chinese Academy of Sciences, Beijing, China.

\begin{abstract}
Much of our knowledge of human uterine physiology and pathology has been extrapolated from the study of diverse animal models, as there is no ideal system for studying human uterine biology in vitro. Although it remains debatable whether mouse models are the most suitable system for investigating human uterine function(s), gene-manipulated mice are considered by many the most useful tool for mechanistic analysis, and numerous studies have identified many similarities in female reproduction between the two species. This Review brings together information from studies using animal models, in particular mouse models, that shed light on normal and pathologic aspects of uterine biology and pregnancy complications.
\end{abstract}

\section{The uterus: a privileged place for new life}

Early in the history of medicine, the uterus was considered a root of women's mental health. Hippocrates conceived the term "hysteria" (from the Greek word for uterus, bystera) to explain a femalespecific mental condition originating from perturbation of the uterus (1). We now know that the uterus does not contribute to such psychologic problems, but it remains a compound source of many female-specific pathologic conditions.

The uterus is part of the urogenital system, which begins to develop in the embryo soon after gastrulation (a process fundamental for formation of the three embryonic layers). It arises from structures known as the Müllerian ducts (MDs) - a pair of ducts that run down the lateral sides of the embryonic urogenital ridge and form the oviducts, uterus, cervix, and upper portion of the vagina - in a process that requires an intricate interplay of many genes (2). To perform its ultimate reproductive function, the uterus is equipped to undergo a finite number of cycles under the regulation of ovarian sex steroid hormones. During these recurring cycles, the endometrial cells lining the uterine cavity proliferate and then regress but are never depleted and do not proliferate out of the normal range (Figure 1) (3). If this tight regulation is somehow perturbed, conditions in the uterus adversely influence fertility, providing some of the many obstacles that reduce the rate of successful human term pregnancy to only $30 \%$ of eggs that contact sperm (4). Chromosomal aberrations are the main reason underlying the low rate of successful human term pregnancies, but other major pregnancy complications that reduce the rate of successful human term pregnancy include ectopic pregnancy, preterm birth, intrauterine growth retardation (IUGR), and preeclampsia (5-7).

Ethical issues are a fundamental restriction to the study of human pregnancy, as it is virtually impossible to obtain proper human samples for cellular and molecular studies. Indeed, observations using medical devices and a small number and size of endometrial biopsies have been the primary sources from which information on the pathophysiology of the human endometrium has been gathered. Another restriction to studying human uterine biology is that there is no ideal cell culture system that truly suffices for studying the intricate cell-cell interactions that occur

Conflict of interest: The authors have declared that no conflict of interest exists. Citation for this article: J Clin Invest. 2010;120(4):1004-1015. doi:10.1172/JCI41210. among several major cell types in the uterus. These restrictions mean that rats and mice have been used extensively to study mammalian reproductive functions for decades, with the mouse becoming the favored model system following the advent of gene-targeting technology (8). An in-depth understanding of the reproductive cycle of mice has therefore accumulated, and this information has enabled the design of more complex models bearing multiple gene deficiencies to comprehend uterine biology at the molecular and cellular level. In this Review, we provide an overview of the current understanding of human uterine physiology and pathology and pregnancy complications based on studies in mice.

\section{Overview of the physiologic role of the uterus in pregnancy}

The female reproductive tract, including the uterus, develops from the MDs between the 9th and 12th weeks of human pregnancy (9). In mice, formation of the uterus is evident at E16.5 (2). Although the process of MD formation seems conserved across many mammalian species, uterine morphology varies between species as a result of differences in the extent of fusion of the anterior portions of the two MDs (2). As depicted in Figure 2, fusion is more extensive in humans than in mice, which have two separate uteri, each with a single oviduct.

The anteroposterior patterning of the MD into the oviduct, uterus, cervix, and upper vagina seems to be governed primarily by $5^{\prime}$ genes of the homeobox A cluster (Hoxa) in mice (10). As in segmental patterning of the vertebrate column by Hoxa genes, the MD takes a "segmental identity" along its long axis by expressing certain Hoxa genes in tightly defined portions. Specifically, Hoxa9, Hoxa10, Hoxa11, and Hoxa13 serve to demarcate boundaries for the oviduct, uterus, and upper part of the vagina (Figure 2). Expression of Hoxa genes in the uterus seems conserved in mice and humans (11). Naturally, any stimulus causing perturbation of these genes beyond their boundaries begets functional and structural complications of the reproductive tract $(10,12)$. For example, autosomal-dominant mutation of the human HOXA13 gene has been reported to cause hand-foot-genital syndrome, which is characterized by limb malformations and urogenital defects. In females, the latter can include incomplete MD fusion. Although this does not prevent successful term pregnancy, it can increase the risk of pregnancy loss, premature labor, and stillbirth (12). 


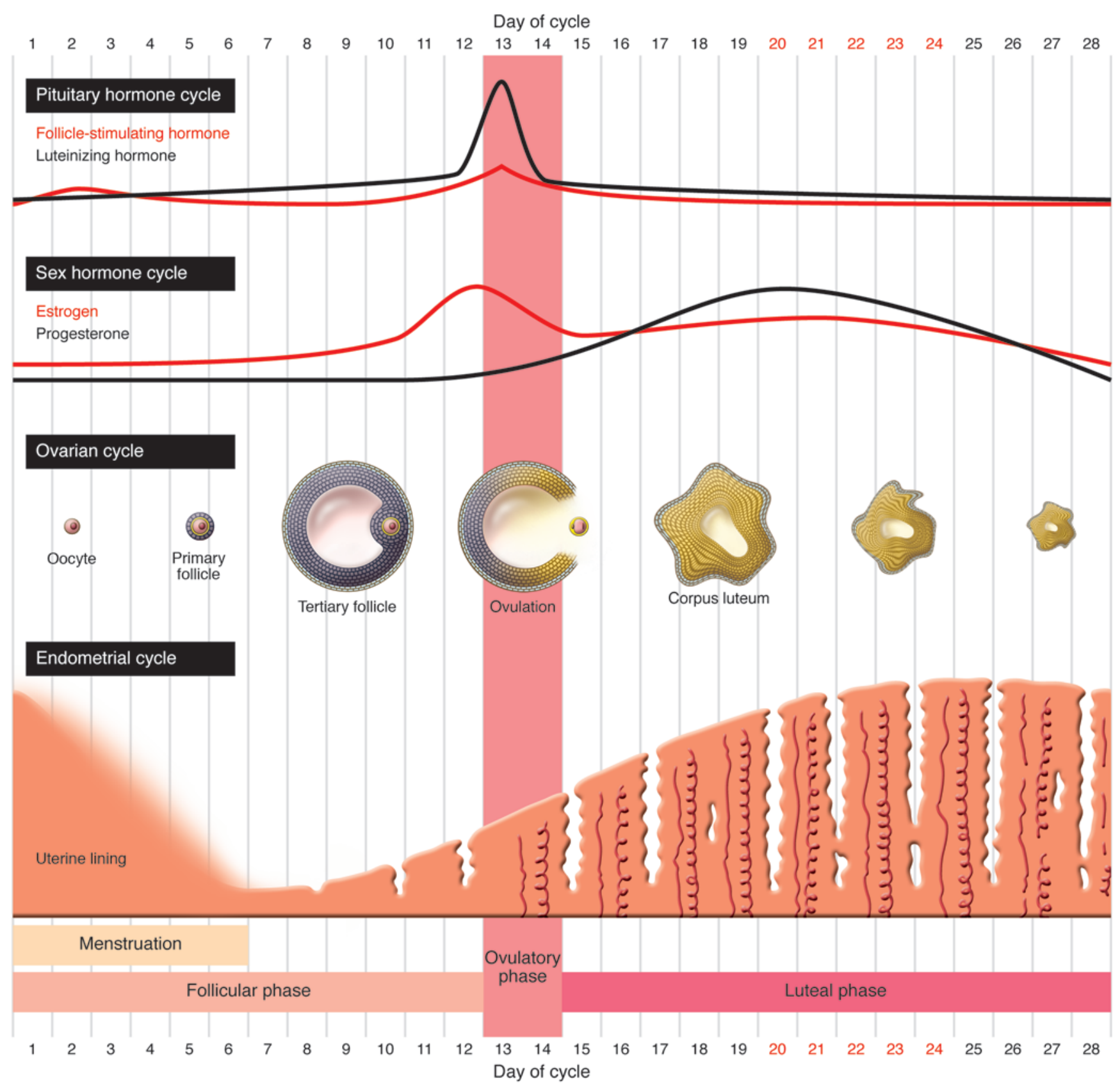

Figure 1

The menstrual cycle in women. The uterus undergoes a sequence of cellular transformations every 28 days. Prior to ovulation, the uterus is at the follicular phase and has a thinner endometrium. Accompanied by peaks of follicle-stimulating hormone and estrogen, ovulation occurs mid-cycle. The uterine lining then proliferates and becomes predecidual for the preparation of blastocyst implantation. In humans, the receptive phase is considered to be around mid-luteal phase, at days 20-24 of each cycle (numbered in red).

In mice, gestation is 20 days when counted from the day of vaginal plug formation (day 1). Harmonized actions of progesterone $\left(\mathrm{P}_{4}\right)$ and estrogen secreted from freshly formed corpora lutea establish the receptivity of the uterus for implantation. A preovulatory estrogen surge induces heavy proliferation of uterine epithelial cells on day 1 , while rising levels of $\mathrm{P}_{4}$ together with preimplantation estrogen secreted on the morning of day 4 induce stromal cell proliferation to establish an optimal milieu for blastocyst attachment to the uterine lining. Implantation occurs only when the uterus is receptive to the presence of blastocysts. Transferring blastocysts into pseudopregnant females has been used to determine when the uterus is sensitive to implantation in mice (13). The uterus is prereceptive on days 1-3 and becomes refractory to implantation by the afternoon of day 5 . Although blastocysts transferred into a prereceptive mouse uterus can survive until it becomes receptive for implantation, the uterine environment is unfavorable to blastocyst survival during the refractory phase (8). Initiation of implantation occurs on the night of day 4 (day 4.5 at 


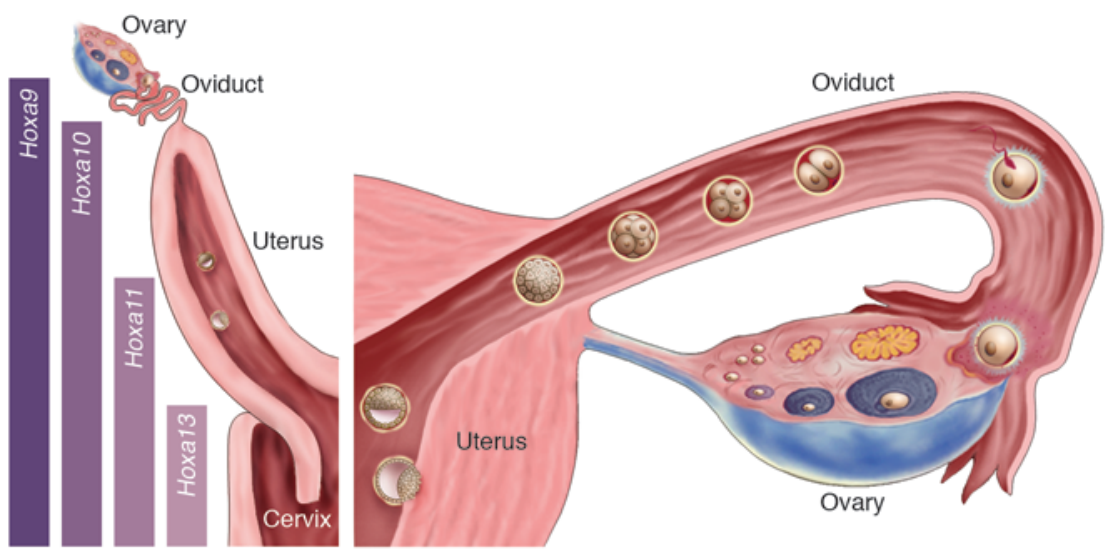

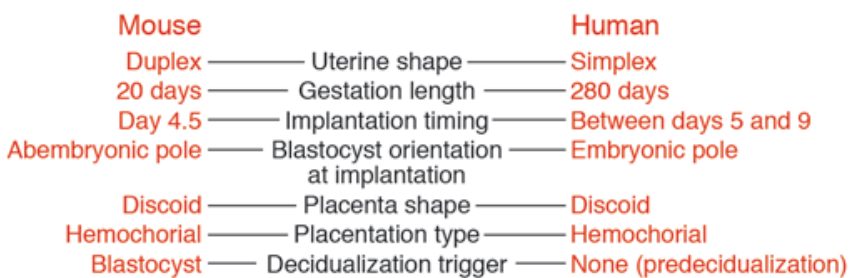

Figure 2

Pregnancy overview: mouse versus human. Columns on the left show distinct boundaries of Hoxa gene expression in the reproductive tract. Demarcation of expression boundaries is based on observations in the mouse; although HOXA genes are also implicated in human reproduction, whether the expression patterns are similar to those in mice is not known.

ine epithelial cell proliferation (22). Subsequently, the postovulatory increase in $\mathrm{P}_{4}$ levels induces profound remodeling and differentiation of the estrogen-primed stromal cells into decidual cells that are large and polyploid (20). Unlike in rodents, decidualization occurs in humans in the absence of an embryo, although the extent of decidualization is enhanced by implantation. This process is crucial for embryo implantation and maintenance of the pregnancy (13).

Signaling molecules mediating crosstalk between the embryo and uterus during implantation have been comprehensively summarized in recent reviews $(8,13,23$, 24). The scope of this Review is two-fold. First, we summarize studies on gene networks regulating the process of endometrial growth and decidualization in mice and find links with current human data. Second, we highlight animal models of pregnancy complications and pregnancy loss to find possible molecular connections with the human conditions.

\section{Molecular regulation of uterine growth and decidualization}

As mentioned, the major difference in decidualization between mice and

2,200-2,300 hr). Increased vascular permeability at the attachment site, which entails the beginning of implantation in mice, is also first seen around this time (13). At the molecular level, cross-talk between the closely situated blastocyst and uterine epithelium is initiated as early as $4 \mathrm{pm}$ of day $4(14,15)$. Uterine blood circulation is provided through blood vessels bundled at one side, dubbed the "mesometrial side," of the uterus (Figure 3). Blastocysts attach to the luminal epithelium at the opposite side, the antimesometrial side. Here, the luminal epithelium undergoes apoptosis (16), allowing the blastocyst to adhere to the uterine lining and trophoblast cells (embryonic cells that contribute to the placenta) to penetrate through the stroma in a regulated manner. Coincidently, stromal cells immediately surrounding the implanting blastocyst proliferate extensively and then differentiate into specialized cells that are polyploid (17). This process (decidualization) is first initiated at the antimesometrial side and forms a structure (the deciduum) that encases the fetus and placenta. In mice, this structure is sustained until placentation but is reduced to a thin layer of cells called the decidua capsularis (Figure 3). Decidual cells become polyploidy by undergoing several rounds of DNA replication without cytokinesis (18). The deciduum is a transient tissue but is presumed to perform several functions crucial to a successful term pregnancy. For example, it is involved in the exchange of nutrients, gas, and waste, and it secretes hormones, growth factors, and cytokines that help maintain the pregnancy $(19,20)$.

The window of implantation in humans is considered to be 5-9 days after ovulation, i.e., the middle of the luteal phase of the menstrual cycle (days 20-24) (Figure 1) (21). The human uterus is considered prereceptive prior to these days and becomes refractory thereafter (21). As in mice, implantation in humans requires a preovulatory increase in estrogen secretion, which stimulates uter- humans is that, in mice, the process requires the attachment of the blastocyst to the uterine lining as a trigger. Despite this difference, both the hormonal requirements for decidualization and the behavior of cells during decidualization are thought to be similar between mice and humans (8). In many genetically engineered mice, gene products involved in different aspects of decidualization have been identified (Table 1). As human decidualization occurs even in the absence of blastocyst attachment to the uterine lining, we discuss herein the factors involved in mouse stromal cell growth and decidualization that are not overtly influenced by the attachment reaction.

Regulation of steroid hormone responsiveness. Ovarian $\mathrm{P}_{4}$ and estrogen are the principal hormones that regulate uterine growth and differentiation during early pregnancy (13). These hormones influence uterine functions primarily via nuclear estrogen and $\mathrm{P}_{4}$ receptors (ERs and PRs, respectively). There are two isoforms each for ER (ER $\alpha$ and ER $\beta$ ) and PR (PRA and PRB). While estrogen signaling is considered dispensable for decidualization, it is crucial for blastocyst attachment to the uterine lining $(25,26)$. In the uterus, $\mathrm{ER} \alpha$ is the major functional receptor for estrogens, as indicated by the observation that $\mathrm{Era}^{-/-}$uteri are hypoplastic and unable to support implantation (27), while Erb-/- uteri support implantation (28). A recent study using an inhibitor of aromatase, a key enzyme in estradiol synthesis, suggested that de novo synthesis of estrogen by the deciduum is critical for decidualization (29). However, two previous studies showed that $\mathrm{P}_{4}$ supports decidualization in $\mathrm{Era}^{-/-}$mice in response to an artificial stimulus $(25,26)$, providing genetic evidence that $\mathrm{P}_{4}$ is sufficient for decidualization.

The uterus expresses both PRA and PRB. Female mice lacking both receptors are infertile and have multiple ovarian and uterine defects (30), but these functions are normal in PRB-deficient 
A

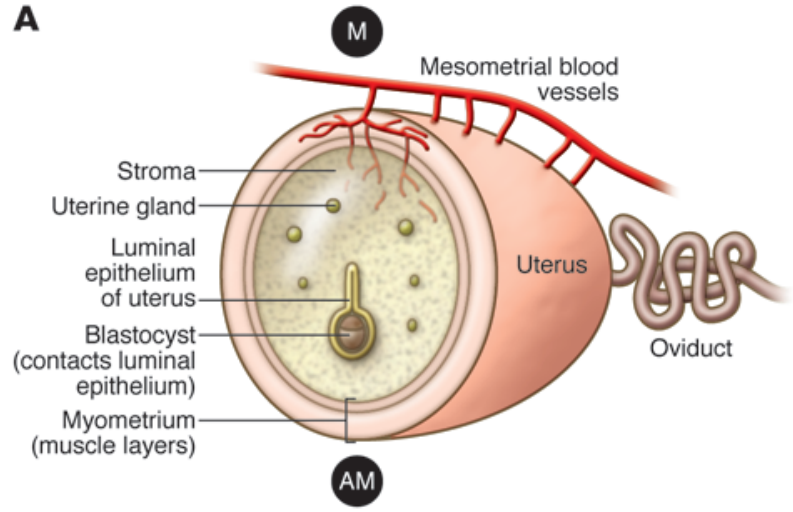

B

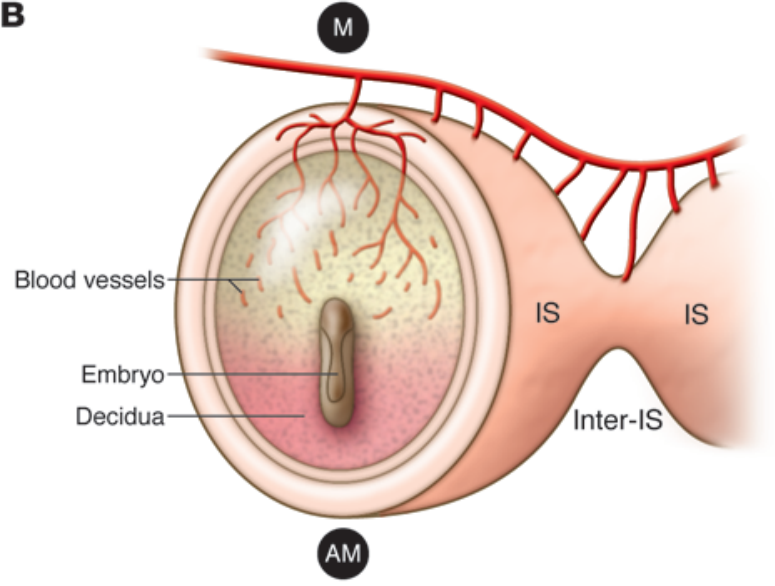

C

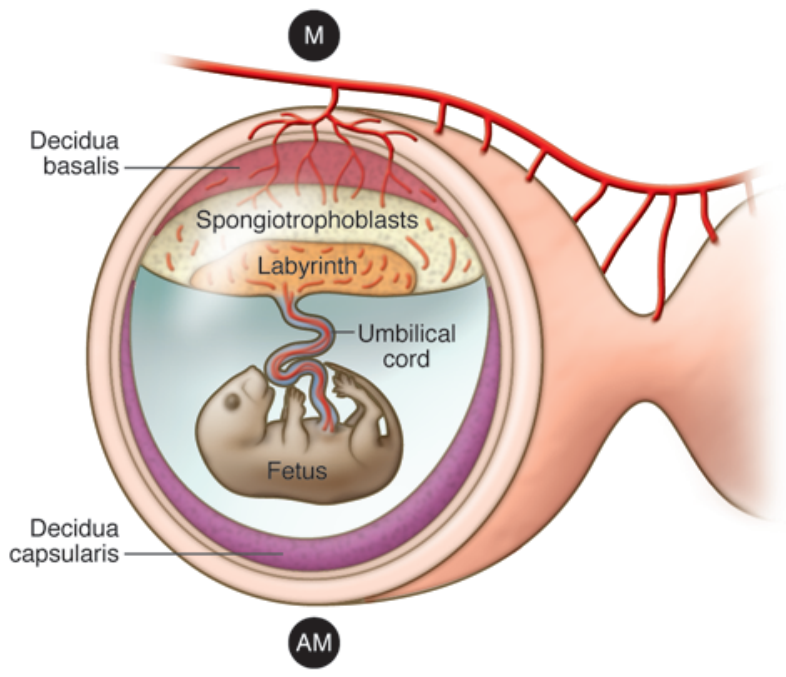

mice (31). Interestingly, PRB-deficient mice also lacking the cyclindependent kinase (CDK) inhibitor p21 are infertile with decidualization defects (18). Thus, while $\mathrm{P}_{4}$-regulated critical functions are primarily mediated by uterine PRA, PRB plays a supporting role in regulating cell cycle progression during decidualization.

As components of the PR-driven transcriptional machinery, steroid receptor coactivator 1 (SRC-1), SRC-2, and SRC-3 - encoded by $N C O A 1, N C O A 2$, and $N C O A 3$, respectively - are important sig-

\section{Figure 3}

Decidualization and placentation in mice. Schematic diagrams depicting cross-sections of implantation sites on days 4,7 , and 13 of pregnancy. (A) On day 4, the luminal epithelium closes on an implanting blastocyst. The mural trophectoderm, which is distant from the inner cell mass, contacts the epithelium at the antimesometrial side (AM). The decidual response also starts from the antimesometrial side (not shown). M, mesometrial side. (B) On day 7 , the embryo is much larger, and its ectoplacental cone has penetrated the mesometrial decidua, which is enriched with blood vessels. Differentiated decidual cells now take up most of the implantation site (IS). Note that decidualization does not occur at inter-implantation sites. (C) On day 13, the placenta has developed, and the decidua has regressed to thin layers around the placenta and embryo, known as decidua basalis and decidua capsularis, respectively.

naling intermediates of ligand-activated PR (32). Female mice with a single null mutation of either $\mathrm{Ncoa} 1$ or $\mathrm{Ncoa} 2$ exhibit decreased $\mathrm{P}_{4}$ sensitivity and a substantial reduction in decidualization (33-35). Mice lacking both SRC- 1 and SRC-2 are infertile with a complete block in decidualization (36). In contrast, Ncoa3-null mice have complex reproductive phenotypes, with delayed puberty and prolonged estrous cycles (37) but exhibit normal decidualization (33). Among these cofactors, SRC-2 also acts as a coactivator of PPAR $\delta$ (38), which is involved in regulating decidualization through its function as a nuclear receptor for COX-2-derived prostacyclin (39-41). Thus, SRC-1 and SRC-2 are essential members of the transcriptional machinery required during decidualization.

The activity of PR is optimized by an immunophilin co-chaperone, FK506-binding protein 4 (FKBP52). High-affinity binding of $\mathrm{P}_{4}$ to $\mathrm{PR}$ is achieved in the presence of FKBP52, although a basal level of $\mathrm{P}_{4}$ responsiveness is maintained in its absence (42). The coupling of PR to FKBP52 seems to be a physiologically relevant phenomenon during early pregnancy, since FKBP52-deficient mice express normal levels of $\mathrm{P}_{4}$ but show reduced uterine $\mathrm{PR}$ responsiveness $(42,43)$. This disrupts the balance between $\mathrm{P}_{4}$ and estrogen in the uterus such that the influence of estrogen is enhanced, resulting in implantation failure $(42,43)$. Moreover, these mice show impaired decidualization in response to implanting blastocysts or artificial stimuli $(43,44)$. The phenotype of $\mathrm{P}_{4}$ resistance in FKBP52-deficient female mice can partially be overcome by exogenously supplying $\mathrm{P}_{4}$, but this is dependent on the genetic background of the mice (44).

As indicated above, multiple factors work in concert to regulate steroid hormone signaling in the uterus, and a defect at any level can perturb fertility. Luteal phase defect (LPD) is a heterogeneous endocrine disorder in women that is associated with unexplained repeated implantation failure or pregnancy loss; it is considered a cause of recurrent miscarriage in more than $10 \%$ of cases (45). While the cause of LPD is not well understood, it is often diagnosed when a woman's serum $\mathrm{P}_{4}$ levels are reduced at midluteal phase or when endometrial growth is insufficient to support a pregnancy (45). $\mathrm{P}_{4}$ supplementation is an important treatment option for women with LPD, potentially through its ability to regulate the window of uterine receptivity, but outcomes are often mixed (46). Therefore, it is reasonable to consider other signaling components of steroid hormone receptor pathways when investigating the etiology of LPD. In this regard, the following studies have provided valuable insights. PR downregulation in the luminal epithelium of the human uterus coincides with the establishment of uterine receptivity and does not occur fully in 


\section{Table 1}

Genes implicated in uterine decidualization: results from mutant mice

\begin{tabular}{|c|c|c|c|}
\hline Gene & $\begin{array}{l}\text { Function/putative function } \\
\text { of encoded protein }\end{array}$ & Reproductive phenotype in gene-knockout females & Reference \\
\hline Arntl & Control of the circadian rhythm & Impaired implantation and decidualization due to decreased serum $\mathrm{P}_{4}$ & 149 \\
\hline Bmp2 & Morphogen & Decidualization fails in uterus-specific conditional knockout mice & 76 \\
\hline Ccnd3 & Cell cycle molecule & Subfertility; impaired decidualization & 18 \\
\hline Cdkn1a & Cell cycle molecule and nuclear receptor & $\begin{array}{l}\text { Infertility with decidualization defects in Cdkn1a and Pgr B isoform } \\
\text { double mutant mice }\end{array}$ & 18 \\
\hline Cebpb & Transcription factor & $\begin{array}{l}\text { Infertility with impaired corpus luteum development; } \\
\text { failure in artificially induced decidualization }\end{array}$ & 150,151 \\
\hline Cx43 & Gap junction molecule & Impaired decidualization with defective angiogenesis & 152 \\
\hline Dlgap5 & Cell cycle molecule & Infertility due to impaired implantation and decidualization & 53 \\
\hline Fkbp4 & $\begin{array}{l}\text { Immunophilin co-chaperone protein for } \\
\text { steroid hormone nuclear receptors }\end{array}$ & $\begin{array}{l}\text { Impaired implantation and defective decidualization due to } \\
\text { compromised } \mathrm{P}_{4} \text { function }\end{array}$ & 42,43 \\
\hline Hbegf & Growth factor & $\begin{array}{l}\text { Subfertility; delayed onset of embryo attachment; } \\
\text { impaired decidualization }\end{array}$ & 18,59 \\
\hline$H m \times 3$ & Transcription factor & Impaired implantation and decidualization & 153 \\
\hline Hoxa10 & Transcription factor & Defective decidualization, leading to reduced fertility & 54,154 \\
\hline Hoxa11 & Transcription factor & Infertility due to defective implantation and decidualization & 155 \\
\hline Ihh & Morphogen & $\begin{array}{l}\text { Impaired implantation and decidualization upon conditional } \\
\text { depletion in uteri }\end{array}$ & 73 \\
\hline I/11ra & Cytokine signaling & $\begin{array}{l}\text { Infertility due to impaired decidualization with defective } \\
\text { decidual vasculature }\end{array}$ & $60-62$ \\
\hline KIf9 & Transcription factor & $\begin{array}{l}\text { Uterine hypoplasia and compromised uterine } \mathrm{P}_{4} \text { function; } \\
\text { impaired implantation and decidualization }\end{array}$ & 58 \\
\hline Ncoa1 & Steroid receptor coactivator & $\begin{array}{l}\text { Fertile, but show reduced uterine stromal differentiation } \\
\text { in artificially induced decidualization }\end{array}$ & 35 \\
\hline Ncoa2 & Steroid receptor coactivator & 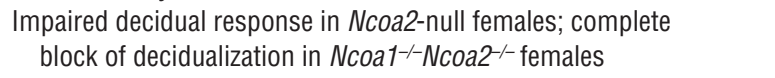 & $33,34,36$ \\
\hline Nr2f2 & Transcription factor & Infertility due to impaired implantation and decidualization & 74,75 \\
\hline Pgr and Pgr A isoforms & Nuclear receptor, transcription factor & Lack of decidual response, even after $\mathrm{P}_{4}$ priming & 30,31 \\
\hline Ppard & Nuclear receptor, transcription factor & $\begin{array}{l}\text { Subfertility; delayed embryo attachment; impaired decidual response; } \\
\text { abnormal angiogenesis in decidual basalis; placental defects }\end{array}$ & 41 \\
\hline Prlr & Receptor & $\begin{array}{l}\text { Irregular cycles; reduced fertilization rates; defective } \\
\text { preimplantation embryo development; lack of pseudopregnancy; } \\
\text { impaired implantation and decidualization }\end{array}$ & 156,157 \\
\hline Ptgs2 & PG synthesis & $\begin{array}{l}\text { Multiple reproductive failures, including defective attachment } \\
\text { and impaired decidualization with reduced angiogenic response }\end{array}$ & $40,49,158$ \\
\hline Ptx3 & Secreted protein & $\begin{array}{l}\text { Subfertility with impaired oocyte maturation and fertilization; } \\
\text { compromised implantation and decidualization }\end{array}$ & 159,160 \\
\hline Sphk1 and Sphk2 & Enzymes & $\begin{array}{l}\text { Sphk1--Sphk2+- females are infertile due to impaired decidualization } \\
\text { with vessel defects }\end{array}$ & 52 \\
\hline Src & Protein tyrosine kinase & Impaired decidualization & 161 \\
\hline
\end{tabular}

the endometrium of women with LPD (47). In the human endometrium, expression of ER, PR, and SRC- 1 are all downregulated in the luteal phase (48), further suggesting that hormone effects can be regulated by differential expression of downstream transcriptional machinery and not just changes in hormone levels. Further investigation with regards to other components of PR signaling may help refine the diagnosis and treatment of LPD.

Lipid-signaling mediators. After the initial attachment reaction, increases in vascular permeability and extensive angiogenesis ensue to support pregnancy. COX-2-derived PGs influence uterine angiogenesis during decidualization by differentially regulating VEGF and angiopoietin signaling cascades (49). Uterine angiogenesis in mice is severely compromised when VEGF, but not angiopoietin, signaling is defective, and this defect is rescued by exogenously supplying a stable prostacyclin agonist (49). In women, circulating levels of VEGF peak approximately 9 days after the luteinizing hormone surge, around the time of implantation (Figure 1) (50). However, it is not clear whether the fluctuation in VEGF levels is directly regulated by PGs, as in mice, or by steroid hormones. 
Sphingolipid metabolites are bioactive lipid signaling molecules generated by sphingosine kinase (Sphk). There are two Sphk isoforms in mammals, Sphk1 and Sphk2, and both are dynamically expressed in postimplantation mouse uteri (51). Sphk $1^{-/-}$Sphk2 $2^{+/-}$mice exhibit defective decidualization, with increased death of decidual cells, decreased proliferation of undifferentiated stromal cells, and massive breakage of decidual blood vessels (52). Perturbation in sphingolipid metabolism thus leads to severe defects in decidualization and early pregnancy loss in mice. The role of sphingolipid signaling in human pregnancy remains to be elucidated.

Control of cell cycle. Decidualization is accompanied by tremendous cell proliferation, differentiation, and endoreplication (duplication of the genome without mitosis), and a complex interplay of cell cycle molecules participates in the process (13). Cyclin D3 is a key player in directing stromal cell proliferation, differentiation, and polyploidization, and its deficiency leads to defective decidualization in mice (18). p21 also has a critical role in this process, as demonstrated by the decidualization defects observed in mice lacking both p21 and PRB (18). Hepatoma upregulated protein (Hurp) is a cell cycle-associated protein expressed at high levels in the $\mathrm{G}_{2} / \mathrm{M}$ phase of the cell cycle. Hurp functions during spindle formation and chromosome congression during mitosis, but a gene-targeting experiment revealed a specific decidualization failure phenotype: Hurp-deficient female mice fail to establish implantation due to an inability to form a deciduum (53).

One candidate regulator of cell cycle molecules during decidualization is Hoxa10, a Hox family transcription factor induced by $\mathrm{P}_{4}$ in the stroma and highly expressed in developing decidua (54). Hoxa10 $10^{-/}$female mice show decidualization defects accompanied by dysregulation of cyclin D3 and loss of region-specific expression of CDK4 and CDK6 in the decidual bed $(17,55)$. In Hoxa10-/- uteri, the cell cycle inhibitors p15 and p57 (56) and the negative cell cycle regulators cyclins G1 and G2 (57) are all abnormally induced. Thus, Hoxa10 in the stroma and decidua may be at the control point of cell cycle progression and cellular differentiation during decidualization. One candidate upstream regulator of Hoxa10 is basic transcription element-binding protein 1 (BTEB1), a PR-interacting protein belonging to the Sp/Kruppel-like family of transcription factors. BTEB1-deficient females mice exhibit decidualization defects with dysregulation of both Hoxa10 and cyclin D3 expression in the uterus (58).

Heparin-binding EGF-like growth factor (HB-EGF) is a unique and versatile mediator of embryo-uterine interactions during implantation both in mice and humans (reviewed in ref. 15). Mice lacking HB-EGF show deferred implantation and compromised decidual growth $(18,59)$. Studies using primary culture of uterine stromal cells have further revealed that HB-EGF induces stromal cell polyploidy and decidualization both in vivo and in vitro by upregulating cyclin D3 expression, reinforcing the role of this protein in decidualization (55).

IL-11 regulates certain uterine functions during early pregnancy. In mice lacking the $\alpha$-chain of the receptor for IL-11 (IL-11R $\alpha$ ), blastocyst attachment to the uterine lining and the initial decidual response occur normally, but decidua degenerate progressively without endoreplication, and placental failure ensues $(60,61)$. Defective polyploidy in Il11 $\mathrm{ra}^{-/-}$decidua results from downregulation of cyclin D3 expression. p21 and survivin are also downstream targets of IL-11 in decidua, and expression of these two proteins is also decreased in Il11 $\mathrm{ra}^{-/-}$decidua (62). These observations further support the idea that cyclin D3 is a key cell cycle molecule regulating stromal proliferation, differentiation, and polyploidy during decidualization.

Study of decidualization in humans has primarily been restricted to an in vitro culture system of human endometrial stromal cells (HESCs). Differentiation of HESCs is generally monitored by changes in cell proliferation rate, output of certain hormones and factors, and gene expression (63). In this system, decidualization of HESCs is induced with either cAMP or $\mathrm{P}_{4}$. A recent study has shown that the transcription factor forkhead box O1 (FOXO1) directly interacts with PR and regulates the expression of genes encoding several cell cycle molecules in HESCs (64). HESCs also produce IL-11, which in turn promotes $\mathrm{P}_{4}$-induced decidualization (65). Of interest in this context, it has been suggested that dysregulation of endometrial IL-11 production is associated with primary infertility in women (66). While a myriad of genes have been implicated in decidualization in this in vitro culture system (63), the information obtained from such studies needs to be further investigated to unravel the complexity of human decidualization in vivo.

Epithelial-mesenchymal interactions during decidualization. There is evidence that decidualization cannot be induced in uteri devoid of epithelial layers, indicating that epithelial layers influence the mesenchymal cells that form decidua (67). A role for the luminal epithelium as a transmitter has been hypothesized to explain the requirement for epithelial cells in decidualization (63), as similar epithelial-mesenchymal interactions occur in many tissues during organogenesis and involve paracrine secretion of specific morphogens (68).

Expression analyses have shown that the hedgehog family morphogen Indian hedgehog ( $\mathrm{IHH}$ ), bone morphogenetic proteins (BMPs), and Wnts are important for establishing uterine receptivity for implantation and for facilitating postimplantation uterine growth (68-72). Ibh is expressed in the receptive uterine epithelium under the control of $\mathrm{P}_{4}(70,71)$. Conditional ablation of $I h b$ in the uterus leads to implantation failure, suggesting that $\mathrm{IHH}$ contributes to the establishment of uterine receptivity under $\mathrm{P}_{4}$ regulation (73). I $h b$-null mice also exhibit decidualization failure in response to an artificial stimulus, which may be due to the perturbed uterine receptivity. The IHH signal from the uterine epithelium seems to be transmitted to the stroma via the receptor patched-1 (Ptch1) and its downstream transcription factors $(70,73)$. One target gene of IHH/Ptch1 encodes chicken ovalbumin upstream promoter-transcription factor II (COUP-TFII) (73). The gene encoding COUP-TFII is expressed in the uterine stroma, and its haploinsufficiency in mice leads to substantially reduced fecundity with impaired decidual response (74). Homozygous deletion of the gene encoding COUP-TFII in the uterine stroma leads to a similar decidualization defect (75). Interestingly, intraluminal supplementation of recombinant BMP2 protein partially restores the decidual response in these mice, suggesting that BMP2 is a downstream target of COUP-TFII in decidualization (75). This idea is consistent with the observation that BMP2deficient uteri show decidualization defects (76). These studies collectively show that the $\mathrm{P}_{4}$-induced IHH/Ptch1/COUP-TFII/ BMP2 pathway is an important constituent of the epithelialmesenchymal cross-talk that is critical for implantation and decidualization. Among the many morphogens implicated in decidualization in the mouse, BMP2 effectively enhances decidualization of HESCs in vitro $(77,78)$. 
As summarized in Table 1, the initiation, progression, and completion of decidualization requires spatiotemporal coordination of various signaling factors. Although the list of genes regulating decidualization is expanding, one should be cautious about judging the involvement of these factors in the process, since it remains largely uncertain whether aberrant expression of so-called downstream genes is due to mutation of a gene of interest or simply the consequence of a defect in decidualization.

Endometrial bypotrophy in women. A thin endometrium is often considered to be a result of impaired endometrial cell growth, and endometrial thickness correlates with pregnancy rate (79). In performing embryo transfer after in vitro fertilization (IVF), several endometrial parameters, including thickness, are assessed to determine the features of the endometrium receiving the transferred embryo (23). A thin endometrium is often associated with low implantation rate, a critical restricting factor in IVF success. Several treatment regimens, including administration of low-dose aspirin, estrogen, or a GnRH agonist, have been used with variable outcomes, suggesting that endometrial hypotrophy is a complex condition caused by poor hormone responsiveness and/or poor endometrial cell growth (80).

Although it is thought that impaired cellular proliferation and differentiation restrict endometrial thickness in women, little is known about the molecular pathways affected. This is despite the enormous amount of knowledge that has accumulated about the molecular networks governing uterine cell proliferation and decidualization in mice. As mentioned earlier, COX-2/PPAR $\delta$ signaling is associated with upregulation of VEGF during uterine angiogenesis, which is required for uterine growth and decidualization. A recent report shows decreased VEGF expression and poor vascular development in thin endometrial tissues from women, indicating that a poor angiogenic response to hormones may be a cause of endometrial hypotrophy (81). Uncovering the molecular and cellular characteristics of thin endometrium in conjunction with the information from mouse models may help increase pregnancy rates following IVF.

\section{Endometriosis: theory and models}

Endometriosis is a common estrogen-dependent pathologic condition of the uterus that occurs in $6 \%-10 \%$ of women of reproductive age. It is characterized by the presence of endometrium-like glandular tissue and stroma outside the uterus, and it is often accompanied by pelvic pain and infertility (82-84). The most widely accepted theory on the pathogenesis of endometriosis is implantation and growth of endometrial tissue within the peritoneal cavity after retrograde menstruation (85). The theory of retrograde menstruation posits that during a woman's menstrual flow, some endometrial debris exits the uterus through the oviducts and attaches to the peritoneal surface, where it can invade the tissue as endometriosis; this is supported by the observation that endometriosis occurs exclusively in species with menstrual cycles (86). However, retrograde menstruation is observed in many women during normal menstruation, but only a small number develop endometriosis. It has also been observed in women with amenorrhea or with complete uterine agenesis $(87,88)$, and in teenagers before menarche (89). An alternative, not necessarily mutually exclusive theory is that endometriosis arises as a result of coelomic metaplasia. This theory proposes that the ovarian germinal epithelium, which is derived from coelomic epithelium, can be transformed by metaplasia into endometrium-like tissue (89). The fact that the pathogenesis of endometriosis remains undetermined indicates that this uterine condition has a complex cellular origin.

Since mice do not develop endometriosis, it has been necessary to use information obtained from human studies to devise model systems to study this disease. The first study providing novel insights into the molecular mechanism of endometriosis followed up the observation that endometriosis patients have an increased incidence of epithelial ovarian cancers (90). Mice overexpressing oncogenic K-ras in the ovarian surface epithelium develop an endometriosis-like disease that does not progress to ovarian cancer (91). However, when these mice are further engineered to lack phosphatase and tensin homolog (PTEN) in the ovarian surface epithelium, they develop invasive ovarian endometrioid adenocarcinomas (91). This work elegantly identifies a link between certain ovarian cancers and endometriosis, and its clinical relevance is indicated by the observation that PTEN mutations are often associated with malignant transformation of endometriosis (reviewed in ref. 92).

The growth of endometriotic tissues is thought to be estrogen dependent, and elevated levels of circulating estradiol are often observed in patients with endometriosis $(93,94)$. Increased expression of aromatase is observed in both ectopic lesions and eutopic endometria in patients with endometriosis, while endometria in women free of disease do not show aromatase expression $(93,95)$. Altered expression of enzymes involved in estrogen metabolism further enhances the accumulation of estradiol in patients with endometriosis $(83,96)$. For example, expression of $17 \beta$-hydroxysteroid dehydrogenase 2 (17- $\beta$ HSD2), which converts estradiol to the much less potent estrone, is suppressed in endometriotic tissues (97-99). 17- $\beta$ HSD2 is also a secondary effector of nuclear $\mathrm{PR}$ signaling and mediates the anti-estrogen function of $\mathrm{P}_{4}$ in the endometrium (100). Thus, the aberrant expression of this enzyme results in estrogen overproduction and $\mathrm{P}_{4}$ resistance, both of which contribute to the etiology of endometriosis.

$\mathrm{P}_{4}$ responsiveness in the eutopic and ectopic endometrium of women with endometriosis is reduced compared with the endometrium of women who do not have endometriosis (101). As demonstrated in $\mathrm{PR}$-deficient mice, $\mathrm{P}_{4}$ resistance due to insufficient levels of functional $\mathrm{PR}$ receptors contributes to the development of endometriosis (102). Consistent with this, a reduction in PRA levels and an absence of PRB expression has been observed in human endometriotic tissues $(96,103)$. As a regulator of PR signaling, FKBP52 might also contribute to $\mathrm{P}_{4}$ resistance in endometriosis. Indeed, FKBP52-deficient mice develop endometriotic lesions characterized by increased inflammation, cell proliferation, and angiogenesis, and FKBP52 is downregulated in eutopic endometria and ectopic lesions of women with endometriosis (104).

A number of gene expression and microarray analyses have been carried out to understand the cause of endometriosis, identifying certain aspects of immune and inflammatory pathways, cell adhesion, cell-cell junctions, extracellular matrix composition, cytoskeleton formation, signal transduction, and apoptotic pathway as altered in endometriotic tissues (105-108). Future studies are needed to characterize the function of these candidate genes and pathways in different types and developmental stages of endometriosis. These studies will require the development of new mouse models, and we hope that they will eventually define the underlying mechanism(s) of endometriosis so that new strategies to combat this disease can be developed. 


\section{Pregnancy loss: wrong place, wrong timing}

While successful term pregnancy is the ultimate function of the uterus, the complex molecular nature of this organ makes it vulnerable to dysfunction that can lead to pregnancy loss, which in humans includes everything from embryonic demise during the preimplantation period to fetal loss in mid- and late gestation. Although uterine dysfunction contributes substantially to pregnancy loss, factors from outside the uterus also have an important role. Pregnancy loss is accompanied or caused by pathological conditions as varied as gamete chromosomal abnormalities, poor embryo quality prior to implantation, deferred or defective implantation, ectopic pregnancy, diabetes and other nutritional problems, and inappropriate maternal immune responses (5, 109-113). Pregnancy loss associated with placental defects and loss of maternal tolerance to the fetus has been extensively reviewed elsewhere $(7,114,115)$. In this section, we therefore discuss other causes of pregnancy loss and pregnancy complications.

Ectopic pregnancy. When an embryo implants at an extrauterine site, embryonic demise follows, along with an increased risk of rupture with hemorrhage, threatening maternal health. Ectopic pregnancy is a leading cause of maternal deaths during early pregnancy (5). While there are identified risk factors, the molecular mechanisms of ectopic pregnancy remain elusive. About $95 \%$ of ectopic pregnancies occur in the Fallopian tube, and tubal infections or pathologies are primary risk factors (5). There is essentially no animal model of ectopic pregnancy, as it has not been reported in organisms other than humans $(112,116)$. Chlamydia infection is considered a major cause of ectopic pregnancy and tubal factor infertility, as the infection often leaves scars in the oviduct tissue (117). Chlamydia infection thus has been used in mice to develop a model system for ectopic pregnancy. In this model, the muscle tone of the oviductal wall is attenuated and the electrical pacemaker potential required for oviductal motility is lost $(116,118)$. Thus, tubal infections increase the chance of ectopic pregnancy by delaying oviductal embryo transport.

Endocannabinoids, such as anandamide ( $N$-arachidonylethanolamine) and 2-arachidonoyl glycerol, are ligands for cannabinoid receptor 1 (CB1) and CB2 (119). Endocannabinoid signaling is closely associated with the establishment of uterine receptivity in mice, and aberrant levels of uterine endocannabinoids or receptors result in pregnancy termination $(120,121)$. Fatty acid amide hydrolase (FAAH) is an endocannabinoid-degrading enzyme, appropriate expression of which is important for maintaining adequate levels of anandamide in the uterus for pregnancy. In $\mathrm{Faah}^{-1-}$ female mice, preimplantation embryo development, ontime implantation, and pregnancy outcome are all adversely affected (122). Endocannabinoid signaling in human reproduction has been extensively investigated in recent years, as marijuana use is frequently linked to poor pregnancy outcome (45). Plasma levels of endocannabinoids fluctuate during menstrual cycles and, as in mice, low levels of endocannabinoids are associated with increased uterine receptivity in women (123). In a similar context, low levels of FAAH were noted in the lymphocytes of IVF patients who failed to become pregnant. These patients also have high plasma levels of endocannabinoids (124).

An increased risk of tubal pregnancy, caused by a delay in embryo transport from the oviduct to the uterus, has been observed in recent studies using CB1- or FAAH-deficient mice $(112,122)$. CB1 is expressed highly in preimplantation embryos and in the oviduct $(112,125)$, and a large number of embryos are retained in the oviducts of CB1-deficient ( $\mathrm{Cnr1^{-/- }}$ ) female mice, a phenomenon that is reversed by the $\beta$-adrenergic agonist isoproterenol. Thus, endocannabinoid signaling is important for regulating the oviductal muscle tone required for normal embryo transport. A similar phenomenon of delayed oviductal embryo transport is observed in $\mathrm{Faah}^{-/}$female mice (122). Consistent with these data, CB1 expression is attenuated in the oviduct and decidua of women with ectopic pregnancy (126). It has also been reported that elevated anandamide levels are often associated with spontaneous pregnancy loss in women $(127,128)$. These studies overall have raised awareness that habitual marijuana use may increase the risk of ectopic pregnancy by dysregulating endocannabinoid signaling.

IUGR and preterm birth: when the problem starts early. In humans, preterm birth refers to a birth that occurs prior to the 37 th week of gestation. It occurs in more than $10 \%$ of all pregnancies in humans and is considered a global risk factor threatening women's health, with $60 \%-80 \%$ perinatal mortality (129). Preterm birth can occur for no apparent reason, but it is frequently associated with preeclampsia, infections, fetal abnormalities, and pregnancy with multiples (6). Preeclampsia is a pregnancy-associated disorder characterized by increased systemic blood pressure and additional symptoms such as proteinuria. The worldwide incidence of preeclampsia is above $5 \%$, and the frequency of incidence has not changed for many years (7). It thus remains a major pregnancy complication in humans. There are compounding causes of preeclampsia, but shallow invasion of trophoblasts during placentation seems to be a leading cause. The resultant poor utero-placental circulation is also a high risk factor for IUGR and preterm birth. This Review focuses on nonplacental origins of preterm birth, and another article in this issue deals with placental pathophysiology.

Bacterial infection can occur in multiple sites within the uterus during pregnancy. Inflammatory responses resulting from the infection are considered a chief culprit of preterm birth, accounting for $40 \%$ of all incidences (130). Maternal responses to a bacterial infection usually accompany increased production of cytokines and chemokines. The fetus responds by increasing corticotrophin-releasing hormone output, and a stress response ensues, with increased adrenal cortisol production (reviewed in ref. 130). Infections associated with preterm birth generally occur during late pregnancy or close to term, and mouse models of preterm birth resulting from maternal infections involve administration of LPS or similar bacterial toxins around E15, which is well beyond placentation (131). Using this model, an important role has been suggested for endothelin-1 in controlling smooth muscle tone in the uterus (132). TLR4 signaling also seems to be involved in regulating PG metabolism, inducing preterm labor in this model $(133,134)$. Overproduction of PGs via COX-2 is noted in the LPS model of preterm birth and is highly associated with increased embryonic resorption in mice (135). Nitric oxide and endocannabinoids are also implicated in LPS-induced tissue damage in the mouse model of preterm birth (136).

The onset of labor in many animals including mice accompanies $\mathrm{P}_{4}$ withdrawal but this is not the case in humans. PGs, on the other hand, are needed for myometrial contraction during labor in both mice and humans. In 15-hydroxyprostaglandin dehydrogenase (15-HPGD) hypomorphic mice, reduced catabolism of PGs during late pregnancy leads to preterm birth, even in the absence of $\mathrm{P}_{4}$ withdrawal (137). In accordance with this observation, reduced 15 -HPGD expression in the fetal membranes in pregnant women is associated with preterm labor (138). 
As mentioned in the previous section, signaling via CB1 is critical for embryo transport from the oviduct to the uterus. Recent work shows that CB1 signaling is also important for on-time parturition (139). Delayed implantation and reduced numbers of embryos in the uteri of normal mice normally lead to delayed parturition, but in $\mathrm{Cnr1}^{-/-}$female mice these features are accompanied by preterm birth. Injection of a CB1 antagonist into pregnant normal mice during late gestation (E14-E18) recapitulates this phenotype, demonstrating that a deferral of implantation in $\mathrm{Cnr1}^{-1-}$ female mice is not associated with the preterm birth phenotype. In these mice, levels of ovarian steroid hormones prior to parturition are perturbed, suggesting that normal endocannabinoid signaling is required to maintain uterine quiescence during late pregnancy (139).

It is now widely accepted that some causes of IUGR and preterm birth originate in early pregnancy. Pregnancy-associated plasma protein-A (PAPP-A) is a placental protein found in the maternal blood from early pregnancy (140). It is a metalloproteinase involved in increasing the bioactivity of the IGF system. A low level of PAPP-A during the first trimester is an important factor associated with low birth weight, which suggests that compromised signaling by the IGF system leads to retarded fetal growth and preterm birth $(141,142)$. Consistent with this system being important for intrauterine fetal growth, mice homozygous for targeted disruption of the gene encoding PAPP-A are born at $60 \%$ of the normal birth weight (143).

Another early risk factor for preterm birth is maternal undernutrition or stress during early pregnancy. In relation to this, suboptimal first-trimester fetal growth shows a high association with premature delivery in humans (144). Undernutrition around the time of conception is implicated as one risk factor for preterm birth. In ewes, undernutrition during the periconceptional period induces a premature surge of circulating fetal cortisol, and this leads to the premature onset of labor (145). In the fetuses of ewes with undernutrition, adrenocorticotropin levels increase precociously, suggesting that this maternal condition perturbs the maturation of the fetal endocrine system (146).

Invasion of trophoblasts begins after the initial attachment of trophoblast cells to uterine epithelial cells. An incompetent attachment reaction propagates into poor implantation and defective postimplantation embryonic growth (8). It is therefore considered an early cause of many pregnancy-associated defects and disorders. Cytosolic phospholipase A2 $\left(\mathrm{CPLA}_{2}\right)$ is a major provider of arachidonic acid for PG synthesis. Uterine deficiency of $\mathrm{CPLA}_{2}$ in mice during early implantation causes PG deficiency with deferred implantation. The outcome is poor embryonic growth with reduced litter size (147). Lysophosphatidic acid (LPA) receptor 3 deficiency results in strikingly similar fetal phenotypes as $\mathrm{CPLA}_{2}$ deficiency in female mice (148). Both mouse mutants exhibit a delay in the attachment reaction, which leads to an IUGR-like phenotype that can be partially corrected by exogenous administration of $\mathrm{PGE}_{2}$ or a $\mathrm{PGI}_{2}$ analog. These results show that PG and LPA are crucial lipid mediators of on-time implantation, something that is important if a pregnancy is to reach full term.

\section{What lies ahead in the field?}

The ultimate goal of researching the mouse uterus is to portray the complexity of the human endometrium. As we have discussed in this Review article and has been noted elsewhere (8, 13, 22-24), the molecular pathways governing uterine biology and pathology in mice have taken more concrete shape over the years. The imminent task for basic scientists and clinicians alike is to translate the mounting information into clinically applicable protocols and therapeutics. A critical issue directly associated with pregnancy rate is providing a suitable uterine environment during the embryo transfer stage of IVF. Two of the many issues that remain to be addressed in the field are determining the uterine receptive phase more accurately by monitoring molecular markers and identifying the molecules that contribute to thin endometrium. Furthermore, it remains to be seen whether the incidence of early reproductive disorders visualized in mouse models is associated with polymorphism or mutation of the human genes.

\section{Acknowledgments}

This work was supported by a National Research Foundation of Korea (NRF) grant funded by the Korea government (MEST, number 2009-A002-0012). H. Wang is a recipient of National Science Foundation for Distinguished Young Scholars grant 30825015 and is supported by the Beijing Natural Science Foundation (grant 5091002) and the National Basic Research Program of China (grant 2010CB945002).

Address correspondence to: Hyunjung Jade Lim, Department of Biomedical Science and Technology, IBST, RCTC, Konkuk University, 1 Hwayang-dong, Kwangjin-gu, Seoul 143-701, Korea. Phone: 82.2.450.4087; Fax: 82.2.2030.7809; E-mail: hlim@konkuk.ac.kr. Or to: Haibin Wang, State Key Laboratory of Reproductive Biology, Institute of Zoology, Chinese Academy of Sciences, 1 Beichen West Road, Chaoyang District, Beijing 100101, China. Phone: 86.10.64807868; Fax: 86.10.64807867; E-mail: hbwang@ioz.ac.cn.
1. Merskey H, Merskey SJ. Hysteria, or "suffocation of the mother". CMAJ. 1993;148(3):399-405.

2. Kobayashi A, Behringer RR. Developmental genetics of the female reproductive tract in mammals. Nat Rev Genet. 2003;4(12):969-980.

3. Gargett CE. Stem cells in gynaecology. Aust NZJ Obstet Gynaecol. 2004;44(5):380-386.

4. Volpe EP. Developmental biology and human concerns. American Zoologist. 1987;27:697-714.

5. Farquhar CM. Ectopic pregnancy. Lancet. 2005;366(9485):583-591.

6. DeFranco E, Teramo K, Muglia L. Genetic influences on preterm birth. Semin Reprod Med. 2007;25(1):40-51.

7. Sibai B, Dekker G, Kupferminc M. Pre-eclampsia. Lancet. 2005;365(9461):785-799.

8. Wang H, Dey SK. Roadmap to embryo implantation: clues from mouse models. Nat Rev Genet.
2006;7(3):185-199.

9. Carlson BM. The urogenital system. In: Human embryology and developmental biology. St. Louis, MO: Mosby; 1994:340-371.

10. Ma L, Benson GV, Lim H, Dey SK, Maas RL. Abdominal $\mathrm{B}(\mathrm{AbdB})$ Hoxa genes: regulation in adult uterus by estrogen and progesterone and repression in mullerian duct by the synthetic estrogen diethylstilbestrol (DES). Dev Biol. 1998;197(2):141-154.

11. Taylor HS, Vanden Heuvel GB, Igarashi P. A conserved Hox axis in the mouse and human female reproductive system: late establishment and persistent adult expression of the Hoxa cluster genes. Biol Reprod. 1997;57(6):1338-1345.

12. Mortlock DP, Innis JW. Mutation of HOXA13 in hand-foot-genital syndrome. Nat Genet. 1997;15(2):179-180.

13. Dey SK, et al. Molecular cues to implantation.
Endocr Rev. 2004;25(3):341-373.

14. Das SK, et al. Heparin-binding EGF-like growth factor gene is induced in the mouse uterus temporally by the blastocyst solely at the site of its apposition: a possible ligand for interaction with blastocyst EGF-receptor in implantation. Development. 1994;120(5):1071-1083.

15. Lim HJ, Dey SK. HB-EGF: a unique mediator of embryo-uterine interactions during implantation. Exp Cell Res. 2009;315(4):619-626.

16. Parr EL, Tung HN, Parr MB. Apoptosis as the mode of uterine epithelial cell death during embryo implantation in mice and rates. Biol Reprod. 1987;36(1):211-225.

17. Tan J, et al. Evidence for coordinated interaction of cyclin D3 with p21 and cdk6 in directing the development of uterine stromal cell decidualization and polyploidy during implantation. Mech 
Dev. 2002;111(1-2):99-113.

18. Das SK. Cell cycle regulatory control for uterine stromal cell decidualization in implantation. Reproduction. 2009;137(6):889-899.

19. Dey SK, Lim H. Implantation. In: Neill JD, ed. Knobil and Neill's physiology of reproduction. St. Louis, MO: Elsevier Academic Press; 2006:147-188.

20. Salamonsen LA, Dimitriadis E, Jones RL, Nie G. Complex regulation of decidualization: a role for cytokines and proteases-a review. Placenta. 2003;24(Suppl A):S76-S85.

21. Wilcox AJ, Baird DD, Weinberg CR. Time of implantation of the conceptus and loss of pregnancy. N Engl J Med. 1999;340(23):1796-1799.

22. Norwitz ER, Schust DJ, Fisher SJ. Implantation and the survival of early pregnancy. $N$ Engl J Med. 2001;345(19):1400-1408.

23. Makker A, Singh MM. Endometrial receptivity: clinical assessment in relation to fertility, infertility, and antifertility. Med Res Rev. 2006;26(6):699-746.

24. Lee KY, Jeong JW, Tsai SY, Lydon JP, DeMayo FJ Mouse models of implantation. Trends Endocrinol Metab. 2007;18(6):234-239.

25. Curtis SW, Clark J, Myers P, Korach KS. Disruption of estrogen signaling does not prevent progesterone action in the estrogen receptor alpha knockout mouse uterus. Proc Natl Acad Sci U S A. 1999;96(7):3646-3651.

26. Paria BC, Tan J, Lubahn DB, Dey SK, Das SK. Uterine decidual response occurs in estrogen receptor-alpha-deficient mice. Endocrinology. 1999;140(6):2704-2710.

27. Lubahn DB, et al. Alteration of reproductive function but not prenatal sexual development after insertional disruption of the mouse estrogen receptor gene. Proc Natl Acad Sci U S A. 1993;90(23):11162-11166.

28. Wada-Hiraike O, et al. Role of estrogen receptor beta in uterine stroma and epithelium: Insights from estrogen receptor beta-/- mice. Proc Natl Acad Sci U S A. 2006;103(48):18350-18355.

29. Das A, et al. De novo synthesis of estrogen in pregnant uterus is critical for stromal decidualization and angiogenesis. Proc Natl Acad Sci U S A. 2009;106(30):12542-12547.

30. Lydon JP, et al. Mice lacking progesterone receptor exhibit pleiotropic reproductive abnormalities. Genes Dev. 1995;9(18):2266-2278.

31. Mulac-Jericevic B, Mullinax RA, DeMayo FJ, Lydon JP, Conneely OM. Subgroup of reproductive functions of progesterone mediated by progesterone receptor-B isoform. Science. 2000;289(5485):1751-1754.

32. McKenna NJ, O'Malley BW. Combinatorial control of gene expression by nuclear receptors and coregulators. Cell. 2002;108(4):465-474.

33 . Jeong JW, et al. The p160 steroid receptor coactivator 2 , SRC-2, regulates murine endometrial function and regulates progesterone-independent and -dependent gene expression. Endocrinology. 2007;148(9):4238-4250.

34. Mukherjee A, et al. Steroid receptor coactivator 2 is critical for progesterone-dependent uterine function and mammary morphogenesis in the mouse. Mol Cell Biol. 2006;26(17):6571-6583.

35. Xu J, et al. Partial hormone resistance in mice with disruption of the steroid receptor coactivator-1 (SRC-1) gene. Science. 1998;279(5358):1922-1925.

36. Mukherjee A, et al. Steroid receptor coactivator 2 is essential for progesterone-dependent uterine function and mammary morphogenesis: insights from the mouse--implications for the human. J Steroid Biochem Mol Biol. 2006;102(1-5):22-31.

37. Xu J, et al. The steroid receptor coactivator SRC-3 (p/CIP/RAC3/AIB1/ACTR/TRAM-1) is required for normal growth, puberty, female reproductive function, and mammary gland development. Proc Natl Acad Sci U S A. 2000;97(12):6379-6384.

38. Lim HJ, Moon I, Han K. Transcriptional cofac- tors exhibit differential preference toward peroxisome proliferator-activated receptors alpha and delta in uterine cells. Endocrinology. 2004; 145(6):2886-2895

39. Lim H, et al. Cyclo-oxygenase-2-derived prostacyclin mediates embryo implantation in the mouse via PPARdelta. Genes Dev. 1999;13(12):1561-1574.

40. Scherle PA, Ma W, Lim H, Dey SK, Trzaskos JM. Regulation of cyclooxygenase- 2 induction in the mouse uterus during decidualization. An event of early pregnancy. J Biol Chem. 2000;275(47):37086-37092.

41. Wang H, et al. Stage-specific integration of maternal and embryonic peroxisome proliferator-activated receptor delta signaling is critical to pregnancy success. J Biol Chem. 2007;282(52):37770-37782.

42. Tranguch $S$, et al. Cochaperone immunophilin FKBP52 is critical to uterine receptivity for embryo implantation. Proc Natl Acad Sci U S A. 2005;102(40):14326-14331.

43. Yang Z, et al. FK506-binding protein 52 is essential to uterine reproductive physiology controlled by the progesterone receptor A isoform. Mol Endocrinol. 2006;20(11):2682-2694.

44. Tranguch S, et al. FKBP52 deficiency-conferred uterine progesterone resistance is genetic background and pregnancy stage specific. J Clin Invest. 2007;117(7):1824-1834.

45. Potdar N, Konje JC. The endocrinological basis of recurrent miscarriages. Curr Opin Obstet Gynecol. 2005;17(4):424-428.

46. Bukulmez O, Arici A. Luteal phase defect: myth or reality. Obstet Gynecol Clin North Am. 2004; 31:727-44, ix.

47. Lessey BA, et al. Endometrial progesterone receptors and markers of uterine receptivity in the window of implantation. Fertil Steril. 1996;65(3):477-483.

48. Shiozawa T, et al. Cyclic changes in the expression of steroid receptor coactivators and corepressors in the normal human endometrium. J Clin Endocrinol Metab. 2003;88(2):871-878.

49. Matsumoto $\mathrm{H}$, et al. Cyclooxygenase- 2 differentially directs uterine angiogenesis during implantation in mice. J Biol Chem. 2002;277(32):29260-29267.

50. Malamitsi-Puchner A, et al. Circulating angiogenic factors during periovulation and the luteal phase of normal menstrual cycles. Fertil Steril. 2004;81(5):1322-1327.

51. Kaneko-Tarui T, et al. Maternal and embryonic control of uterine sphingolipid-metabolizing enzymes during murine embryo implantation. Biol Reprod. 2007;77(4):658-665.

52. Mizugishi K, et al. Maternal disturbance in activated sphingolipid metabolism causes pregnancy loss in mice. J Clin Invest. 2007;117(10):2993-3006.

53. Tsai CY, et al. Hurp deficiency in mice leads to female infertility caused by an implantation defect. J Biol Chem. 2008;283(39):26302-26306.

54. Lim H, Ma L, Ma WG, Maas RL, Dey SK. Hoxa-10 regulates uterine stromal cell responsiveness to progesterone during implantation and decidualization in the mouse. Mol Endocrinol. 1999; 13(6):1005-1017.

55. Tan Y, etal. HB-EGF directs stromal cell polyploidy and decidualization via cyclin D3 during implantation. Dev Biol. 2004;265(1):181-195.

56 . Yao MW, et al. Gene expression profiling reveals progesterone-mediated cell cycle and immunoregulatory roles of Hoxa-10 in the preimplantation uterus. Mol Endocrinol. 2003;17(4):610-627.

57. Yue L, et al. Cyclin G1 and cyclin G2 are expressed in the periimplantation mouse uterus in a cellspecific and progesterone-dependent manner: evidence for aberrant regulation with Hoxa-10 deficiency. Endocrinology. 2005;146(5):2424-2433.

58. Simmen RC, et al. Subfertility, uterine hypoplasia, and partial progesterone resistance in mice lacking the Kruppel-like factor 9/basic transcription element-binding protein-1 (Bteb1) gene. J Biol Chem.
2004;279(28):29286-29294

59. Xie H, et al. Maternal heparin-binding-EGF deficiency limits pregnancy success in mice. Proc Natl Acad Sci US A. 2007;104(46):18315-18320.

60. Bilinski P, Roopenian D, Gossler A. Maternal IL-11Ralpha function is required for normal decidua and fetoplacental development in mice. Genes Dev. 1998;12(14):2234-2243.

61. Robb L, et al. Infertility in female mice lacking the receptor for interleukin 11 is due to a defective uterine response to implantation. Nat Med. 1998;4(3):303-308.

62. Li F, Devi YS, Bao L, Mao J, Gibori G. Involvement of cyclin D3, CDKN1A (p21), and BIRC5 (Survivin) in interleukin 11 stimulation of decidualization in mice. Biol Reprod. 2008;78(1):127-133.

63. Gellersen B, Brosens J. Cyclic AMP and progesterone receptor cross-talk in human endometrium: a decidualizing affair. J Endocrinol. 2003;178(3):357-372.

64. Takano M, et al. Transcriptional cross talk between the forkhead transcription factor forkhead box $\mathrm{O} 1 \mathrm{~A}$ and the progesterone receptor coordinates cell cycle regulation and differentiation in human endometrial stromal cells. Mol Endocrinol. 2007;21(10):2334-2349.

65. Dimitriadis E, Robb L, Salamonsen LA. Interleukin 11 advances progesterone-induced decidualization of human endometrial stromal cells. Mol Hum Reprod. 2002;8(7):636-643.

66. Karpovich N, et al. The production of interleukin-11 and decidualization are compromised in endometrial stromal cells derived from patients with infertility. J Clin Endocrinol Metab. 2005;90(3):1607-1612.

67. Lejeune B, Van Hoeck J, Leroy F. Transmitter role of the luminal uterine epithelium in the induction of decidualization in rats. J Reprod Fertil. 1981;61(1):235-240.

68. Paria BC, et al. Cellular and molecular responses of the uterus to embryo implantation can be elicited by locally applied growth factors. Proc Natl Acad Sci US A. 2001;98(3):1047-1052.

69. Daikoku T, et al. Uterine Msx-1 and Wnt4 signaling becomes aberrant in mice with the loss of leukemia inhibitory factor or Hoxa-10: evidence for a novel cytokine-homeobox-Wnt signaling in implantation. Mol Endocrinol. 2004;18(5):1238-1250.

70. Matsumoto H, Zhao X, Das SK, Hogan BL, Dey SK. Indian hedgehog as a progesterone-responsive factor mediating epithelial-mesenchymal interactions in the mouse uterus. Dev Biol. 2002;245(2):280-290.

71. Takamoto N, Zhao B, Tsai SY, DeMayo FJ. Identification of Indian hedgehog as a progesteroneresponsive gene in the murine uterus. Mol Endocrinol. 2002;16(10):2338-2348.

72. Ying Y, Zhao GQ. Detection of multiple bone morphogenetic protein messenger ribonucleic acids and their signal transducer, Smad1, during mouse decidualization. Biol Reprod. 2000;63(6):1781-1786.

73. Lee $\mathrm{K}$, et al. Indian hedgehog is a major mediator of progesterone signaling in the mouse uterus. Nat Genet. 2006;38(10):1204-1209.

74. Takamoto N, et al. Haploinsufficiency of chicken ovalbumin upstream promoter transcription factor II in female reproduction. Mol Endocrinol. 2005;19(9):2299-2308.

75. Kurihara I, et al. COUP-TFII mediates progesterone regulation of uterine implantation by controlling ER activity. PLoS Genet. 2007;3:e102.

76. Lee $\mathrm{KY}$, et al. Bmp2 is critical for the murine uterine decidual response. Mol Cell Biol. 2007; 27(15):5468-5478.

77. Stoikos CJ, Harrison CA, Salamonsen LA, Dimitriadis E. A distinct cohort of the TGFbeta superfamily members expressed in human endometrium regulate decidualization. Hum Reprod. 2008;23(6):1447-1456

78. Li Q, et al. Bone morphogenetic protein 2 functions via a conserved signaling pathway involving Wnt4 to 
regulate uterine decidualization in the mouse and the human. J Biol Chem. 2007;282(43):31725-31732.

79. Richter KS, Bugge KR, Bromer JG, Levy MJ. Relationship between endometrial thickness and embryo implantation, based on 1,294 cycles of in vitro fertilization with transfer of two blastocyststage embryos. Fertil Steril. 2007;87(1):53-59.

80. Senturk LM, Erel CT. Thin endometrium in assisted reproductive technology. Curr Opin Obstet Gynecol. 2008;20(3):221-228.

81. Miwa I, et al. Pathophysiologic features of "thin" endometrium. Fertil Steril. 2009;91(4):998-1004.

82. Giudice LC, Kao LC. Endometriosis. Lancet. 2004;364(9447):1789-1799

83. Rizner TL. Estrogen metabolism and action in endometriosis. Mol Cell Endocrinol. 2009;307(1-2):8-18.

84. Vinatier D, Orazi G, Cosson M, Dufour P. Theories of endometriosis. Eur J Obstet Gynecol Reprod Biol. 2001;96(1):21-34.

85. Sampson JP. Peritoneal endometriosis due to the menstrual dissemination of endometrial tissue into the peritoneal cavity. Am J Obstet Gynecol. 1927; 14:422-425.

86. D’Hooghe TM, Debrock S. Endometriosis, retrograde menstruation and peritoneal inflammation in women and in baboons. Hum Reprod Update. 2002;8(1):84-88.

87. El-Mahgoub S, Yaseen S. A positive proof for the theory of coelomic metaplasia. Am J Obstet Gynecol. 1980;137(1):137-140

88. Mok-Lin EY, Wolfberg A, Hollinquist H, Laufer MR. Endometriosis in a patient with Mayer-Rokitansky-Kuster-Hauser syndrome and complete uterine agenesis: evidence to support the theory of coelomic metaplasia. J Pediatr Adolesc Gynecol. 2010;23(1):e35-37.

89. Suginami H. A reappraisal of the coelomic metaplasia theory by reviewing endometriosis occurring in unusual sites and instances. Am J Obstet Gynecol. 1991;165(1):214-218.

90. Gemignani ML, et al. Role of KRAS and BRAF gene mutations in mucinous ovarian carcinoma. Gynecol Oncol. 2003;90(2):378-381.

91. Dinulescu DM, et al. Role of K-ras and Pten in the development of mouse models of endometriosis and endometrioid ovarian cancer. Nat Med. 2005;11(1):63-70.

92. Mandai M, Yamaguchi K, Matsumura N, Baba T, Konishi I. Ovarian cancer in endometriosis: molecular biology, pathology, and clinical management. Int J Clin Oncol. 2009;14(5):383-391.

93. Kitawaki J, et al. Expression of aromatase cytochrome $\mathrm{P} 450$ protein and messenger ribonucleic acid in human endometriotic and adenomyotic tissues but not in normal endometrium. Biol Reprod. 1997;57(3):514-519.

94. Takahashi K, Nagata H, Kitao M. Clinical usefulness of determination of estradiol level in the menstrual blood for patients with endometriosis. Nippon Sanka Fujinka Gakkai Zasshi. 1989;41(11):1849-1850.

95. Noble LS, Simpson ER, Johns A, Bulun SE. Aromatase expression in endometriosis. J Clin Endocrinol Metab. 1996;81(1):174-179.

96. Bulun SE, et al. Progesterone resistance in endometriosis: link to failure to metabolize estradiol. $\mathrm{Mol}$ Cell Endocrinol. 2006;248(1-2):94-103.

97. Borghese B, et al. Gene expression profile for ectopic versus eutopic endometrium provides new insights into endometriosis oncogenic potential. Mol Endocrinol. 2008;22(11):2557-2562.

98. Dassen $\mathrm{H}$, et al. Estrogen metabolizing enzymes in endometrium and endometriosis. Hum Reprod. 2007;22(12):3148-3158.

99. Matsuzaki S, Canis M, Pouly JL, Dechelotte PJ, Mage G. Analysis of aromatase and 17betahydroxysteroid dehydrogenase type 2 messenger ribonucleic acid expression in deep endometrio- sis and eutopic endometrium using laser capture microdissection. Fertil Steril. 2006;85(2):308-313.

100.Yang S, et al. Stromal PRs mediate induction of 17beta-hydroxysteroid dehydrogenase type 2 expression in human endometrial epithelium: a paracrine mechanism for inactivation of E2. Mol Endocrinol. 2001;15(12):2093-2105.

101.Minici F, et al. Endometriosis and human infertility: a new investigation into the role of eutopic endometrium. Hum Reprod. 2008;23(3):530-537.

102. Fang $Z$, et al. Intact progesterone receptors are essential to counteract the proliferative effect of estradiol in a genetically engineered mouse model of endometriosis. Fertil Steril. 2004;82(3):673-678.

103. Attia GR, et al. Progesterone receptor isoform A but not $\mathrm{B}$ is expressed in endometriosis. J Clin Endocrinol Metab. 2000;85(8):2897-2902.

104. Hirota Y, et al. Deficiency of immunophilin FKBP52 promotes endometriosis. Am J Pathol. 2008;173(6):1747-1757.

105. Eyster KM, Klinkova O, Kennedy V, Hansen KA. Whole genome deoxyribonucleic acid microarray analysis of gene expression in ectopic versus eutopic endometrium. Fertil Steril. 2007;88(6):1505-1533.

106. Honda H, Barrueto FF, Gogusev J, Im DD, Morin PJ. Serial analysis of gene expression reveals differential expression between endometriosis and normal endometrium. Possible roles for AXL and SHC1 in the pathogenesis of endometriosis. Reprod Biol Endocrinol. 2008;6:59.

107. Matsuzaki S, et al. Differential expression of genes in eutopic and ectopic endometrium from patients with ovarian endometriosis. Fertil Steril. 2006;86(3):548-553.

108. Meola J, et al. Differentially expressed genes in eutopic and ectopic endometrium of women with endometriosis [published online ahead of print February 5, 2009]. Fertil Steril. doi:10.1016/j.fertnst ert.2008.12.058.

109. Moley KH. Hyperglycemia and apoptosis: mechanisms for congenital malformations and pregnancy loss in diabetic women. Trends Endocrinol Metab. 2001;12(2):78-82.

110. Girardi G, et al. Complement $\mathrm{C} 5$ a receptors and neutrophils mediate fetal injury in the antiphospholipid syndrome. J Clin Invest. 2003;112(11):1644-1654.

111. Erlebacher A, Zhang D, Parlow AF, Glimcher LH. Ovarian insufficiency and early pregnancy loss induced by activation of the innate immune system. J Clin Invest. 2004;114(1):39-48.

112. Wang $\mathrm{H}$, et al. Aberrant cannabinoid signaling impairs oviductal transport of embryos. Nat Med. 2004;10(10):1074-1080.

113.Girardi G. Complement inhibition keeps mothers calm and avoids fetal rejection. Immunol Invest. 2008;37(5):645-659.

114.Caucheteux SM, Kanellopoulos-Langevin C, Ojcius DM. At the innate frontiers between mother and fetus: linking abortion with complement activation. Immunity. 2003;18(2):169-172.

115. Trowsdale J, Betz AG. Mother's little helpers: mechanisms of maternal-fetal tolerance. Nat Immunol. 2006;7(3):241-246.

116.Hunter RH. Tubal ectopic pregnancy: a pathophysiological explanation involving endometriosis. Hum Reprod. 2002;17(7):1688-1691.

117. World Health Organization. Global strategy for the prevention and control of sexually transmitted infections:2006-2015. Breaking the chain of transmission. Geneva: WHO; 2007.

118. Dixon RE, et al. Chlamydia infection causes loss of pacemaker cells and inhibits oocyte transport in the mouse oviduct. Biol Reprod. 2009;80(4):665-673.

119. Wang H, Dey SK, Maccarrone M. Jekyll and hyde: two faces of cannabinoid signaling in male and female fertility. Endocr Rev. 2006;27(5):427-448.

120.Paria BC, et al. Dysregulated cannabinoid signaling disrupts uterine receptivity for embryo implantation.
Biol Chem. 2001;276(23):20523-20528.

121. Wang H, et al. Differential G protein-coupled cannabinoid receptor signaling by anandamide directs blastocyst activation for implantation. Proc Natl Acad Sci US A. 2003;100(25):14914-14919.

122. Wang H, et al. Fatty acid amide hydrolase deficiency limits early pregnancy events. J Clin Invest. 2006;116(8):2122-2131.

123. Habayeb OM, et al. Plasma levels of the endocannabinoid anandamide in women--a potential role in pregnancy maintenance and labor? J Clin Endocrinol Metab. 2004;89(11):5482-5487.

124. Maccarrone $\mathrm{M}$, et al. Low fatty acid amide hydrolase and high anandamide levels are associated with failure to achieve an ongoing pregnancy after IVF and embryo transfer. Mol Hum Reprod. 2002;8(2):188-195.

125.Paria BC, Das SK, Dey SK. The preimplantation mouse embryo is a target for cannabinoid ligand-receptor signaling. Proc Natl Acad Sci U S A. 1995;92(21):9460-9464.

126. Horne AW, et al. CB1 expression is attenuated in Fallopian tube and decidua of women with ectopic pregnancy. PLoS One. 2008;3:e3969.

127. Habayeb OM, Taylor AH, Finney M, Evans MD, Konje JC. Plasma anandamide concentration and pregnancy outcome in women with threatened miscarriage. JAMA. 2008;299(10):1135-1136.

128. Maccarrone $\mathrm{M}$, et al. Relation between decreased anandamide hydrolase concentrations in human lymphocytes and miscarriage. Lancet. 2000;355(9212):1326-1329.

129. Rush RW, Keirse MJ, Howat P, Baum JD, Anderson AB, Turnbull AC. Contribution of preterm delivery to perinatal mortality. Br MedJ. 1976;2:965-968.

130.Goldenberg RL, Hauth JC, Andrews WW. Intrauterine infection and preterm delivery. $N$ Engl J Med. 2000;342(20):1500-1507.

131. Elovitz MA, Mrinalini C. Animal models of preterm birth. Trends Endocrinol Metab. 2004;15(10):479-487.

132. Wang W, et al. The endothelin-converting enzyme-1/ endothelin-1 pathway plays a critical role in inflammation-associated premature delivery in a mouse model. Am J Pathol. 2008;173(4):1077-1084.

133. Wang H, Hirsch E. Bacterially-induced preterm labor and regulation of prostaglandin-metabolizing enzyme expression in mice: the role of toll-like receptor 4. Biol Reprod. 2003;69(6):1957-1963.

134.Elovitz MA, Wang Z, Chien EK, Rychlik DF, Phillippe M. A new model for inflammationinduced preterm birth: the role of platelet-activating factor and Toll-like receptor-4. Am J Pathol. 2003;163(5):2103-2111.

135.Aisemberg J, et al. Nitric oxide mediates prostaglandins' deleterious effect on lipopolysaccharidetriggered murine fetal resorption. Proc Natl Acad Sci US A. 2007;104(18):7534-7539.

136.Vercelli CA, Aisemberg J, Billi S, Wolfson ML, Franchi AM. Endocannabinoid system and nitric oxide are involved in the deleterious effects of lipopolysaccharide on murine decidua. Placenta. 2009;30(7):579-584.

137. Roizen JD, Asada M, Tong M, Tai HH, Muglia LJ. Preterm birth without progesterone withdrawal in 15-hydroxyprostaglandin dehydrogenase hypomorphic mice. Mol Endocrinol. 2008;22(1):105-112.

138.Sangha RK, Walton JC, Ensor CM, Tai HH, Challis JR. Immunohistochemical localization, messenger ribonucleic acid abundance, and activity of 15hydroxyprostaglandin dehydrogenase in placenta and fetal membranes during term and preterm labor. J Clin Endocrinol Metab. 1994;78(4):982-989.

139.Wang H, Xie H, Dey SK. Loss of cannabinoid receptor CB1 induces preterm birth. PLoS One. 2008;3(10):e3320.

140. Overgaard MT, et al. Messenger ribonucleic acid levels of pregnancy-associated plasma protein-A and the proform of eosinophil major basic protein: 
expression in human reproductive and nonreproductive tissues. Biol Reprod. 1999;61(4):1083-1089.

141.Smith GC, et al. Early pregnancy levels of pregnancy-associated plasma protein a and the risk of intrauterine growth restriction, premature birth, preeclampsia, and stillbirth.J Clin Endocrinol Metab. 2002;87(4):1762-1767.

142.Smith GC, et al. Early-pregnancy origins of low birth weight. Nature. 2002;417:916.

143. Conover CA, et al. Metalloproteinase pregnancyassociated plasma protein A is a critical growth regulatory factor during fetal development. Development. 2004;131(5):1187-1194.

144.Smith GC, Smith MF, McNay MB, Fleming JE. First-trimester growth and the risk of low birth weight. N Engl J Med. 1998;339(25):1817-1822.

145. Bloomfield FH, et al. A periconceptional nutritional origin for noninfectious preterm birth. Science. 2003;300:606.

146. Bloomfield FH, et al. Brief undernutrition in lategestation sheep programs the hypothalamic-pituitary-adrenal axis in adult offspring. Endocrinology. 2003;144(7):2933-2940.

147. Song H, et al. Cytosolic phospholipase A2alpha is crucial [correction of A2alpha deficiency is crucial] for 'on-time' embryo implantation that directs subsequent development. Development. 2002;129(12):2879-2889.

148. Ye X, et al. LPA3-mediated lysophosphatidic acid signalling in embryo implantation and spacing. Nature. 2005;435(7038):104-108.

149. Ratajczak CK, Boehle KL, Muglia LJ. Impaired steroidogenesis and implantation failure in Bmal1-/mice. Endocrinology. 2009;150(4):1879-1885.

150.Sterneck E, Tessarollo L, Johnson PF. An essential role for C/EBPbeta in female reproduction. Genes Dev. 1997;11(17):2153-2162.

151. Mantena SR, et al. C/EBPbeta is a critical mediator of steroid hormone-regulated cell proliferation and differentiation in the uterine epithelium and stroma. Proc Natl Acad Sci U S A. 2006;103(6):1870-1875.

152. Laws MJ, et al. Gap junction communication between uterine stromal cells plays a critical role in pregnancyassociated neovascularization and embryo survival Development. 2008;135(15):2659-2668.

153. Wang W, Van De Water T, Lufkin T. Inner ear and maternal reproductive defects in mice lacking the Hmx3 homeobox gene. Development. 1998;125(4):621-634.

154.Benson GV, Lim H, Paria BC, Satokata I, Dey SK, Maas RL. Mechanisms of reduced fertility in Hoxa-10 mutant mice: uterine homeosis and loss of maternal Hoxa-10 expression. Development. 1996;122(9):2687-2696.

155. Hsieh-Li HM, et al. Hoxa 11 structure, extensive antisense transcription, and function in male and female fertility. Development. 1995;121(5):1373-1385.

156. Ormandy CJ, et al. Null mutation of the prolactin receptor gene produces multiple reproductive defects in the mouse. Genes Dev. 1997;11(2):167-178.

157. Reese J, et al. Implantation and decidualization defects in prolactin receptor (PRLR)-deficient mice are mediated by ovarian but not uterine PRLR. Endocrinology. 2000;141(5):1872-1881.

158. Lim H, et al. Multiple female reproductive failures in cyclooxygenase 2-deficient mice. Cell. 1997;91(2):197-208.

159.Tranguch S, Chakrabarty A, Guo Y, Wang H, Dey SK. Maternal pentraxin 3 deficiency compromises implantation in mice. Biol Reprod. 2007; 77(3):425-432.

160.Varani S, et al. Knockout of pentraxin 3, a downstream target of growth differentiation factor-9, causes female subfertility. Mol Endocrinol. 2002;16(6):1154-1167.

161.Shimizu A, et al. Impairment of decidualization in SRC-deficient mice. Biol Reprod. 2005; 73(6):1219-1227. 